\title{
Synaptic Release of Serotonin Induced by Stimulation of the Raphe Nucleus Promotes Plateau Potentials in Spinal Motoneurons of the Adult Turtle
}

\author{
Jean-François Perrier ${ }^{1}$ and Rodolfo Delgado-Lezama ${ }^{2}$ \\ ${ }^{1}$ Department of Medical Physiology, Panum Institute, University of Copenhagen, DK-2200 Copenhagen N, Denmark, and ²Departamento de Fisiología, \\ Biofísica y Neurociencias, Centro de Investigación y de Estudios Avanzados, 07000-México, México
}

\begin{abstract}
Serotonin (5-HT) is a major modulator of the CNS. In motoneurons recorded in slices of the spinal cord, 5-HT promotes plateau potentials mediated by the activity of low-threshold L-type calcium channels $\left(\mathrm{Ca}_{\mathrm{V}} 1.3\right)$. However, no direct evidence has shown that 5 -HT actually promotes plateau potentials under physiological conditions. Here, we investigate how release of 5-HT induced by activation of the raphe nucleus modulates intrinsic properties of spinal motoneurons. We developed an integrated preparation of the brainstem left in continuity with the cervical segments of the spinal cord from adult turtles. Electrical stimulation of the raphe nucleus increased the excitability of motoneurons by decreasing the amplitude of the afterhyperpolarization following action potentials and by promoting plateau potentials. Antagonists of 5- $\mathrm{HT}_{2}$ receptors applied in the vicinity of motoneurons inhibited the facilitation of plateaus. In a slice preparation in which glutamatergic, GABAergic, and glycinergic ionotropic synaptic transmission was blocked, stimulation of the dorsolateral funiculus facilitated a plateau potential by promoting a voltage-sensitive persistent inward current. This effect was inhibited by the addition of antagonists for $5-\mathrm{HT}_{2}$ receptors. Our study suggests that $\mathrm{Ca}_{\mathrm{V}} 1.3$ channels are regulated by 5 -HT released from raphe spinal synaptic terminals via $5-\mathrm{HT}_{2}$ receptors.
\end{abstract}

Key words: brainstem; spinal cord; raphe; serotonin; motoneuron; synaptic transmission

\section{Introduction}

Movements generated by the nervous system are mediated by an appropriate temporal sequence of action potentials in motoneurons. The mechanisms involved in adjustment of discharge patterns in motoneurons therefore play a fundamental role in motor control. In addition to synaptic inputs, electric currents flowing through ion channels present in the neuronal membrane provide a form of cellular plasticity that is important for the shaping of discharge patterns (Llinas, 1988). A plateau potential is a stable membrane potential that can be maintained in the absence of ongoing stimulation and is an example of such intrinsic property (Schwindt and Crill, 1977; Hounsgaard and Mintz, 1988; Hounsgaard et al., 1988). In spinal motoneurons, plateau potentials are mediated by a persistent inward current generated by lowthreshold L-type $\mathrm{Ca}^{2+}$ channels $\left(\mathrm{Ca}_{\mathrm{V}} 1.3\right)$ (Schwindt and Crill, 1977; Hounsgaard and Mintz, 1988; Svirskis and Hounsgaard, 1997; Perrier and Hounsgaard, 1999; Carlin et al., 2000). These dihydropyridine-sensitive channels are facilitated by preceding depolarization, which provides a form of short-term memory for

Received May 17, 2005; revised July 19, 2005; accepted July 19, 2005.

This work was supported by the Danish Medical Research Council, The Foundation Agnes and Poul Friis, The Carlsberg Foundation, The Lundbeck Foundation, The Ambassade de France au Danemark, and the Consejo Nacional de Ciencia y Tecnologia.

Correspondence should be addressed to Dr. Jean-François Perrier, Medicinsk Fysiologisk Institut, Panum Institute, University of Copenhagen, Blegdamsvej 3, DK-2200 Copenhagen N, Denmark. E-mail: perrier@mfi.ku.dk. DOI:10.1523/JNEUROSCI.1957-05.2005

Copyright $\odot 2005$ Society for Neuroscience $\quad$ 0270-6474/05/257993-07\$15.00/0 neurons (Russo and Hounsgaard, 1994; Morisset and Nagy, 1996; Derjean et al., 2003) ranging from hundreds of milliseconds to tens of seconds (Delgado-Lezama et al., 1997; Perrier et al., 2002). Many studies suggest that plateau potentials are recruited under physiological conditions (Eken and Kiehn, 1989; Kiehn and Eken, 1997; Gorassini et al., 1999; Alaburda and Hounsgaard, 2003; Perrier and Tresch, 2005). They may contribute to behaviors by amplifying synaptic inputs to motoneurons (Conway et al., 1988; Hultborn, 1999; Lee and Heckman, 2000) or by specifying the temporal details of motor output (Perrier and Tresch, 2005).

Several lines of evidence suggest that plateau potentials in motoneurons are latent properties that need to be unmasked by neuromodulatory agents such as serotonin (5-HT). In vivo experiments showed that bistability in cat motoneurons disappears after spinalization and reappears after intravenous injection of the 5-HT precursor 5-hydroxytryptophan (Crone et al., 1988; Hounsgaard et al., 1988b). Experiments performed in vitro demonstrated that 5-HT directly added to the extracellular medium promotes plateau potentials in motoneurons (Hounsgaard and Kiehn, 1989; Hsiao et al., 1998; Bennett et al., 2001; Perrier and Tresch, 2005) by activating 5- $\mathrm{HT}_{2}$ receptors (Perrier and Hounsgaard, 2003). 5-HT is thus undoubtedly facilitating plateau potentials in motoneurons. However, the demonstration that under physiological conditions 5-HT actually promotes plateau potentials is still lacking.

In the spinal cord, 5-HT is mainly released from neurons be- 
longing to the raphe spinal pathway. They project to dorsal horns and to ventral horns where they contact motoneurons through a high density of synaptic contacts (Kiehn et al., 1992; Alvarez et al., 1998). Raphe neurons are tonically active in awake animals and discharge at a frequency correlated with the level of motor activity (Jacobs and Fornal, 1997). This suggests that during movement, 5 -HT is steadily released on motoneurons.

Here, we demonstrate that synaptic release of 5-HT induced by stimulation of the raphe nucleus promotes plateau potentials in turtle motoneurons. Pharmacological analysis shows that this effect is attributable to activation of $5-\mathrm{HT}_{2}$ receptors specifically facilitating low-threshold L-type calcium channels.

\section{Materials and Methods}

Adult turtles (Chrysemys scripta elegans) were anesthetized by intraperitoneal injection of $100 \mathrm{mg}$ of sodium pentobarbitone and killed by decapitation. The surgical procedures complied with the Danish legislation and were approved by the controlling body under The Ministry of Justice. Experiments were performed at room temperature $\left(20-22^{\circ} \mathrm{C}\right)$. Because turtles are poikilothermic animals, this temperature is physiological. Preparations were perfused in a solution containing the following (in mm): $120 \mathrm{NaCl}, 5 \mathrm{KCl}, 15 \mathrm{NaHCO}_{3}, 2 \mathrm{MgCl}_{2}, 3 \mathrm{CaCl}_{2}$, and 20 glucose saturated with $98 \% \mathrm{O}_{2}$ and $2 \% \mathrm{CO}_{2}$ to obtain $\mathrm{pH}$ 7.6.

Brainstem spinal cord preparation. The brainstem of the turtle contains two raphe nuclei: the nucleus raphe superior and the nucleus raphe inferior (Parent and Poirier, 1971; Cruce and Nieuwenhuys, 1974; Ueda et al., 1983). Both nuclei are located on the midline and form two continuous columns (Kiehn et al., 1992). The nucleus raphe inferior, which projects to the spinal cord, is probably homologous to the mammalian raphe pallidus, raphe obscurus, and raphe magnus nuclei (Ueda et al., 1983; Kiehn et al., 1992). The axons of the nucleus raphe inferior are located in a large dorsolateral tract and a smaller ventrolateral tract (Ten Donkelaar, 1976; Kiehn et al., 1992). The spinal cord of the turtle also contains few serotonergic somata, all located in proximity to the central canal (Kiehn et al., 1992). Stimulation of the dorsolateral funiculus (DLF) is therefore unlikely to recruit any of these cells.

The portion of the CNS consisting of the caudal half of the brainstem and the cervical enlargement of the spinal cord was placed in vitro without removing the surrounding bone. Most of the surrounding muscles were removed. The remaining parts were paralyzed with gallamine triesthiodide $(20 \mathrm{mg} / \mathrm{ml}$; Sigma, St. Louis, MO). The sides of the rostral and caudal ends of the preparation were glued to a Plexiglas plate so that the cut surfaces of the spinal cord and the brainstem faced upward. A catheter inserted in the subdural space at the level of the brainstem allowed continuous perfusion of Ringer's solution. A bipolar electrode (TM33CCNON; World Precision Instruments, Sarasota, FL) was positioned on the ventral midline of the cut surface of the brainstem section (see Fig. 1A), at the location of the nucleus raphe inferior (Cruce and Nieuwenhuys, 1974). The raphe nucleus was stimulated either with single shocks or with trains of shocks $(10-20$ shocks applied at $10 \mathrm{~Hz})$. Drugs were applied at the cut end of the spinal cord by means of a local superfusion system consisting of an inlet and an outlet (see Fig. 2C). The continuous perfusion of the spinal cord with Ringer's solution (see Figs. $1 A, 2 B$, arrows) prevented drugs from penetrating the tissue deeply.

Slice preparation. Slices from the spinal cord of the turtle were placed in a chamber superfused continuously with Ringer's solution. Extracellular stimulation of the DLF (see Fig. $3 A$ ) was performed by applying $10-40$ shocks at $10 \mathrm{~Hz}$ by means of a bipolar electrode (TM33CCNON; World Precision Instruments).

Recordings. Intracellular recordings in current-clamp and voltageclamp mode were performed with an Axoclamp 2B amplifier (Molecular Devices, Union City, CA). Pipettes were filled with a mixture of $\mathrm{KCl}(0.1$ $\mathrm{M})$ and K-acetate $(0.9 \mathrm{M})$. Motoneurons were identified with the criterions defined by Hounsgaard et al. (1988a) [i.e., location in the lateral part of the ventral horn; input resistance ranging from 10 to $50 \mathrm{M} \Omega$; response to depolarizing current pulse with repetitive firing and with an adaptation of the firing frequency; presence of a fast and slower afterhyperpolarization (AHP) after each action potential]. Motoneurons were selected for study if they had a stable membrane potential more hyperpolarized than $-55 \mathrm{mV}$. For voltage-clamp experiments, the capacitance of the pipette was reduced by coating the tip with Sylgard (Dow-Corning, Midland, MI). Action potentials were blocked by lidocaine $N$-ethyl bromide (QX-314; $0.1 \mathrm{M}$; Sigma) applied through the microelectrode. Voltageclamp recordings were performed in discontinuous service mode to avoid any deviation from the tip of the microelectrode from the command voltage. The sample rate for the clamp was of $6.8-8.6 \mathrm{kHz}$, and the gain was $0.7-1.5 \mathrm{nA} \cdot \mathrm{mV}^{-1}$. A low-pass filter cutoff setting of $0.1 \mathrm{kHz}$ was applied. Data were sampled at $10 \mathrm{kHz}$ with a 16-bit analog-to-digital converter (DIGIDATA 1322A; Molecular Devices) and displayed by means of the Axoscope software (Molecular Devices).

Drugs. N-3-pyridinyl-3,5-dihydro-5-methylbenzo(1,2-b:4,5-b') dipyrrole-1 $(2 \mathrm{H})$ carboxamide hydrochloride (SB-206553 hydrochloride; $10 \mu \mathrm{M}$; Sigma) was used to block $5-\mathrm{HT}_{2}$ receptors. For all of the experiments performed in slices, synaptic potentials were inhibited by blocking fast synaptic receptors with a mixture of CNQX (25 $\mu \mathrm{m}$; Tocris, Ellisville, $\mathrm{MO})$, DL-AP-5 (50 $\mu \mathrm{M}$; Tocris), strychnine (10 $\mu \mathrm{M}$; Sigma), and bicuculline (20 $\mu \mathrm{M}$; Sigma).

Analysis. Data were analyzed statistically by using a two-population (paired or independent when appropriate) $t$ test (Origin software; Microcal, Northampton, MA). Significance was accepted when $p<0.05$. Data are presented as means \pm SEM.

\section{Results}

Stimulation of the raphe nucleus promotes plateau potentials in motoneurons

We tested the excitability of spinal motoneurons recorded in the brainstem spinal cord preparation by intracellular injection of depolarizing current pulses. In the example shown in Figure $1 B$, the motoneuron responded with a train of action potentials with a frequency that slightly increased during the pulse. Electrical stimulation of the raphe nucleus $(20$ shocks, $10 \mathrm{~Hz}$ ) applied $3 \mathrm{~s}$ before the depolarizing current pulse facilitated a plateau potential (Fig. 1C). The frequency of action potentials increased more than in control conditions. In addition, an afterdepolarization that was sufficient to trigger action potentials was present after the current pulse was turned off (Fig. 1C, arrow).

It was originally suggested that the promotion of plateau potentials by 5 -HT is attributable to the inhibition of the afterhyperpolarization (AHP) following action potentials (Hounsgaard and Mintz, 1988; Hounsgaard and Kiehn, 1989). We therefore tested whether stimulation of the raphe nucleus inhibited the AHP. Figure $1 D$ shows the recording of an action potential evoked by a strong depolarizing current pulse ( $4 \mathrm{nA}, 4 \mathrm{~ms})$ in a spinal motoneuron. Under control conditions, the spike was followed by a fast and a slower AHP that had an amplitude of -1.5 $\mathrm{mV}$ (Fig. $1 \mathrm{D}$ ). When the raphe nucleus was stimulated by a single electrical shock applied $300 \mathrm{~ms}$ before the action potential, the amplitude of the slow component of the AHP was reduced to $-0.9 \mathrm{mV}$ (i.e., a decrease of $40 \%$ ) (Fig. $1 \mathrm{E}$ ). Inhibition of the slower component of the AHP by raphe stimulation was recorded in six motoneurons (mean inhibition, $21.5 \pm 11.3 \%$; $p<0.01$ ).

To test whether the facilitation of plateau potentials occurred independently of the inhibition of the AHP, we adjusted the amplitude of depolarizing current pulses to the threshold for action potentials. In the example illustrated in Figure $2 \mathrm{~A}$, a control depolarizing current pulse generated no action potentials. However, after stimulation of the raphe nucleus (10 shocks at $10 \mathrm{~Hz}$ ), the same depolarizing current pulses applied $0.5,4.5$, and $8.5 \mathrm{~s}$ after the stimulation generated seven, eight, and six action potentials, respectively. A similar increase in excitability induced by raphe nucleus stimulation was recorded in 11 motoneurons (Fig. $2 D$, left). The increase in excitability induced by stimulation of the raphe nucleus peaked during the first current pulse and grad- 


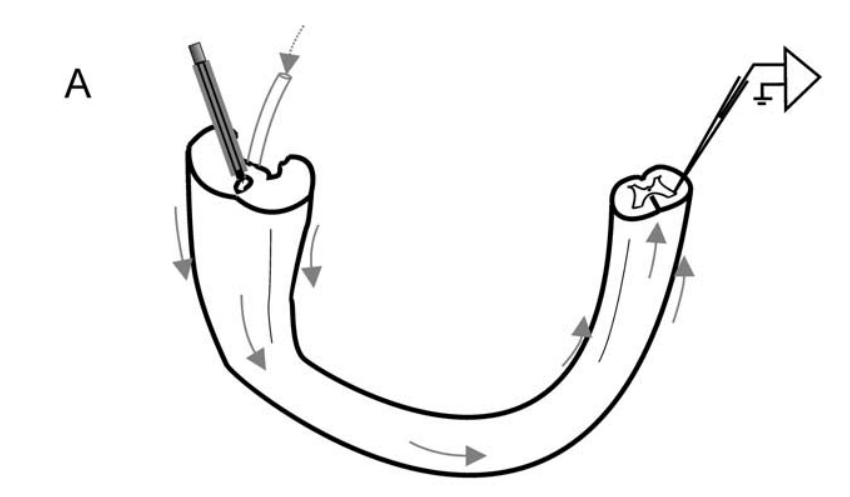

B

Before Raphé stimulation

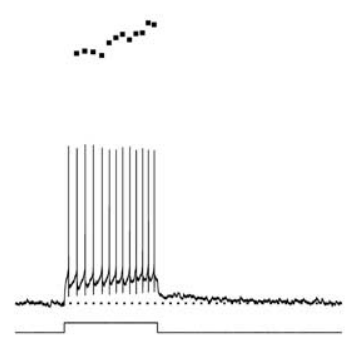

C

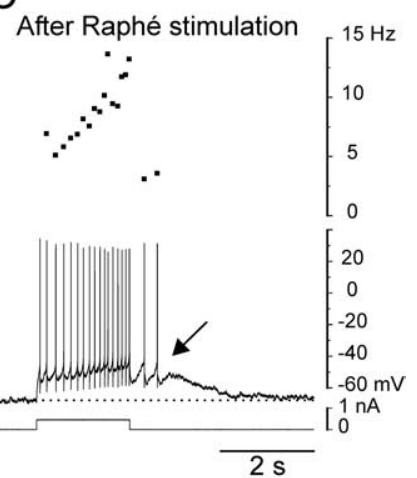

D

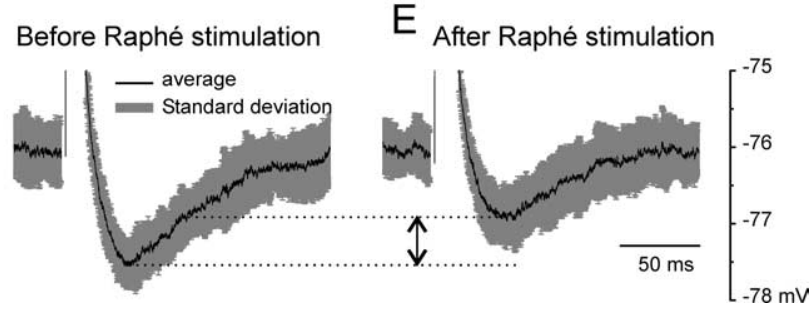

Figure 1. Stimulation of the raphe nucleus promotes plateau potentials in spinal motoneurons. $A$, Scheme of the brainstem spinal cord preparation. A catheter inserted between the backbone and the brainstem was continuously perfusing the preparation with Ringer's solution (arrows). A bipolar electrode was positioned at the ventral third of the midline of the brainstem section (i.e., at the level of the raphe nucleus) (see Materials and Methods). Intracellular recording of motoneurons was performed with a microelectrode positioned in the lateral part of the ventral horn of the spinal cord section. $\boldsymbol{B}$, Control response to a depolarizing current pulse. $\boldsymbol{C}$, After stimulation of the raphe nucleus, the same current protocol induced a train of action potentials occurring at a higher frequency and followed by an afterdepolarization with a superimposed afterdischarge (arrow), indicative of an underlying plateau potential. For $\boldsymbol{B}$ and $\boldsymbol{C}$ : bottom trace, current injected intracellularly; middle trace, membrane potential; top plot, instantaneous spike frequency. $\boldsymbol{D}$, Average response of a motoneuron to depolarizing current pulses in control conditions (average of 20 consecutive traces; SD in gray). $\boldsymbol{E}$, Average response of the same motoneuron when the depolarizing current pulse was preceded by stimulation of the raphe nucleus $300 \mathrm{~ms}$ before the depolarizing current pulse. Note the inhibition of the AHP. The action potential was cut to fit in the frame of the figure.

ually decreased after the stimulation. It remained statistically significant after $8.5 \mathrm{~s}$ and was back to normal after $13.5 \mathrm{~s}( \pm 3.6 ; n=$ 10; data not shown). Because control pulses were applied at the threshold level for action potentials, it is likely that the facilitation was not only caused by inhibition of the AHP.

Facilitation of plateau potentials involves $5-\mathrm{HT}_{2}$ receptors

In the preceding paragraph, we showed that synaptic release of transmitter, induced by the activity of the raphe nucleus, generates an increase in excitability that lasts several seconds. However, besides 5-HT, raphe neurons also release other neuromodulators
A
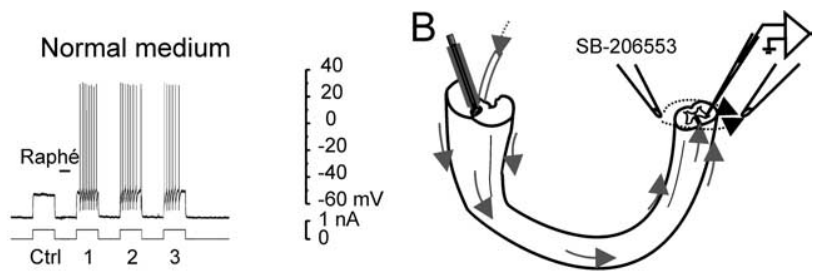

C

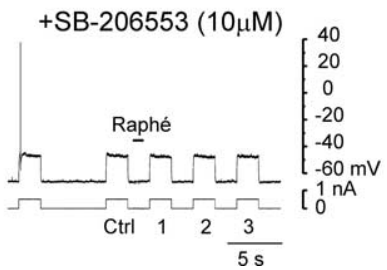

D

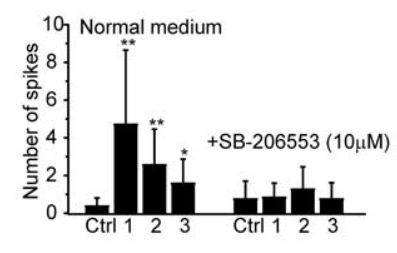

Figure 2. The increase in excitability induced by raphe stimulation involves $5-\mathrm{HT}_{2}$ receptors. $A$, Response of a motoneuron before (Ctrl) and after stimulation of the raphe nucleus $(1,2,3)$. The excitability increased for $>8 \mathrm{~s}$. B, Scheme of the preparation. The superfusion system applying SB-206553 at the cut level of the spinal cord (black dotted arrows) is shown. C, The same motoneuron as in $A$, recorded during superfusion of SB-206553. No additional potentiation of the response is observed. $\boldsymbol{D}$, Summary plot of the number of spikes induced by each depolarizing current pulse in normal medium $(n=11)$ and during the superfusion of SB206553 for the different motoneurons recorded $(n=4)$. Statistical difference before and after raphe stimulation in normal medium $\left({ }^{*} p<0.05 ;{ }^{* *} p<0.01\right.$ ) but not in the presence of SB-206553 is shown. Ctrl, Control.

such as enkephalin or substance P (Uhl et al., 1979; Inagaki et al., 1981; Schmidt and Jordan, 2000). In addition, although the stimulus electrode was positioned in the region of the raphe nucleus, we cannot exclude that some of the recruited fibers were not serotonergic. To ensure that the increase in excitability recorded in motoneurons was actually attributable to synaptic release of 5-HT, we performed pharmacological experiments by applying an antagonist at the cut end of the spinal cord through a local superfusion system (Fig. $2 \mathrm{~B}$ ). Because 5 -HT promotes plateau potentials in turtle motoneurons by activating $5-\mathrm{HT}_{2}$ receptors (Perrier and Hounsgaard, 2003), we tested the effect of SB206553, a selective antagonist for these receptors. Figure $2 C$ shows a recording obtained from the same motoneuron as in Figure 2A, but during the superfusion of SB-206553. Depolarizing current pulses of the same amplitude as in normal medium generated zero or one action potential (Fig. 2C, first two pulses), showing that the threshold for action potentials remained unchanged. However, stimulation of the raphe nucleus no longer potentiated the response induced by depolarizing current pulses. We observed the same effect in four of four motoneurons from four different preparations (Fig. $2 D$, right) (paired $t$ test; $p>$ 0.05). This experiment confirms that synaptic release of 5-HT induced by electrical stimulation of the raphe nucleus facilitates plateau potentials in motoneurons. Moreover, it demonstrates that $5-\mathrm{HT}_{2}$ receptors are involved in the facilitation.

\section{Stimulation of the DLF reproduces the effect induced by stimulation of the raphe nucleus}

The results obtained with the integrated preparation can be interpreted in two different ways: SB-206553 inhibited the facilitation either by blocking $5-\mathrm{HT}_{2}$ receptors located on motoneurons or by inhibiting receptors located at the premotor level. To circumvent this limitation of the preparation, we pursued our investigation in a slice preparation from the spinal cord. The raphe spinal pathway was stimulated by means of a microelectrode located on the DLF (Fig. $3 A$ ), a major pathway for descending 
A

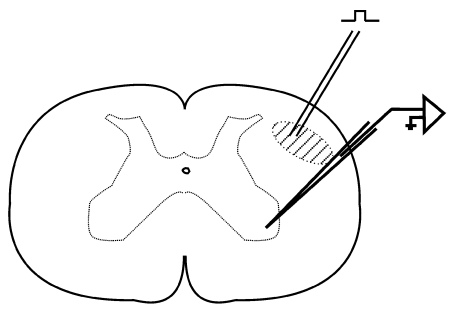

B

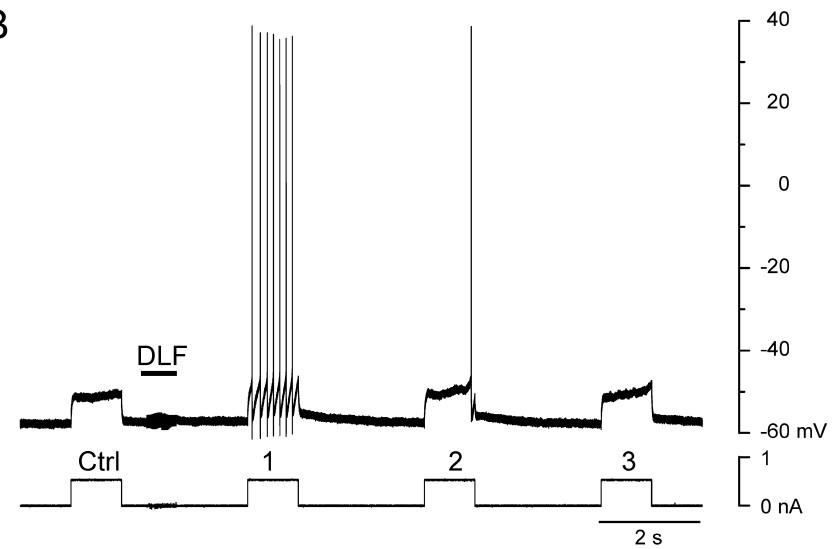

C

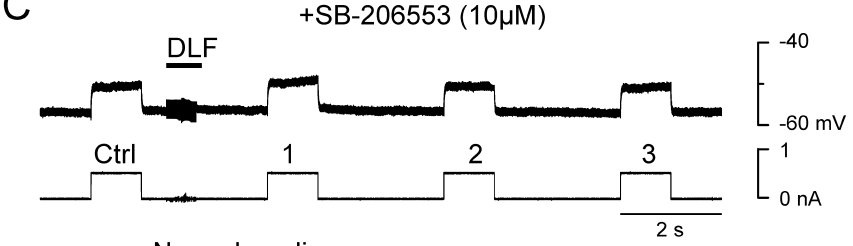

D

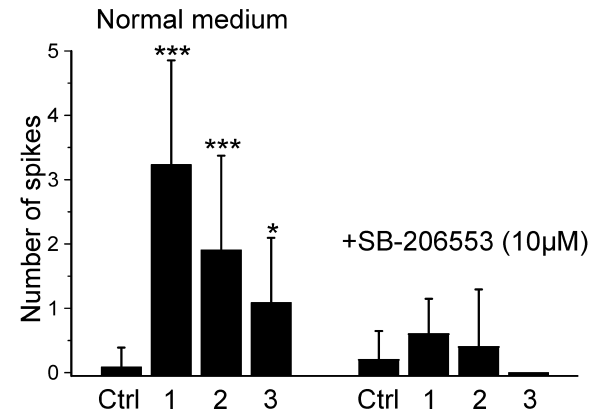

Figure 3. Stimulation of the DLF on a slice preparation increases motoneuron excitability. $A$, Scheme of the preparation for stimulation and recording. $\boldsymbol{B}$, Response of a motoneuron before (Ctrl) and after stimulation of the DLF $(1,2,3)$. The excitability increased for $>8 \mathrm{~s}$. C, The same motoneuron recorded after the addition of SB-206553. No additional potentiation of the response was observed. $\boldsymbol{D}$, Summary plot of the number of spikes induced by each depolarizing current pulse in normal medium $(n=11)$ and after the addition of SB-206553. Statistical differences before and after DLF stimulation in normal medium $\left({ }^{*} p<0.05\right.$; ${ }^{* * *} p<0.001$ ) but not in the presence of SB-206553 $(n=5)$ is shown. For all recordings, fast synaptic potentials were blocked by CNQX (25 $\mu \mathrm{M})$, AP-5 $(50 \mu \mathrm{M})$, strychnine $(10 \mu \mathrm{M})$, and bicuculline $(20 \mu \mathrm{M})$. Ctrl, Control.

serotonergic fibers in reptiles (Ten Donkelaar, 1976) including turtles (Kiehn et al., 1992). Fast synaptic potentials were blocked by a mixture of antagonists for ionotropic receptors (see Materials and Methods). Motoneuron excitability was tested as in the integrated preparation, by intracellular injection of depolarizing current pulses with an amplitude adjusted to the level for spiking threshold. Figure $3 B$ shows the recording from a motoneuron obtained with this set-up. A depolarizing current pulse generated no action potential. After stimulation of the DLF ( 30 shocks at 25
$\mathrm{Hz}$ ), the same depolarizing current pulse applied 0.5, 4.5, and $8.5 \mathrm{~s}$ after the stimulation generated seven, one, and zero action potentials, respectively. Similar increase in excitability induced by DLF stimulation was recorded in 11 of 11 motoneurons tested (Fig. 3D, left). The increase in excitability gradually decreased after stimulation of the DLF but remained statistically significant up to $8.5 \mathrm{~s}$ after.

To test whether the stimulus-induced increase in excitability in motoneurons was attributable to activation of $5-\mathrm{HT}_{2}$ receptors, we added SB-206553 to the extracellular medium. Figure 3C shows a recording obtained from the same motoneuron as in Figure $3 B$, but in the presence of the $5-\mathrm{HT}_{2}$ receptor antagonist. Electrical stimulation of the DLF no longer increased the excitability of the motoneuron. Consistent results were obtained in five of five motoneurons tested (Fig. 3D, right). In the presence of SB-206553, DLF stimulation no longer increased the number of spikes generated by a depolarizing current pulse ( $p>0.05$; paired $t$ test). These results show that synaptic release of $5-\mathrm{HT}$ increases the excitability of motoneurons by activating $5-\mathrm{HT}_{2}$ receptors.

\section{Synaptic activation of $5-\mathrm{HT}_{2}$ receptors facilitates a low-} threshold, voltage-sensitive inward current

A previous study ascribed the increase in excitability induced by DLF stimulation to the facilitation of a plateau potential mediated by L-type $\mathrm{Ca}^{2+}$ channels because it was abolished by nifedipine (Delgado-Lezama et al., 1997). To test whether the increase in excitability induced by synaptic activation of $5-\mathrm{HT}_{2}$ receptors also involved L-type $\mathrm{Ca}^{2+}$ channels, we performed voltageclamp experiments. The protocol consisted of $20 \mathrm{mV}$ triangular voltage depolarizations applied from $-60 \mathrm{mV}$ (Fig. 4A1). Stimulation of the DLF facilitated a voltage-sensitive, slowly activating inward current (Fig. 4A1, gray trace) responsible for the clockwise hysteresis configuration in $I-V$ plots ( $n=7$ of 7 ) (Fig. 4A2). Motoneuron input resistance measured as the slope of $I-V$ plots during the first second of voltage ramps was not significantly affected by DLF stimulation (Fig. $4 D$ ) (paired $t$ test; $p>0.05 ; n=$ 7). In the presence of SB-206553, the response recorded before stimulation of the DLF was unaffected (Fig. 4A1,B1, compare black traces). However, the facilitation of the inward current induced by DLF stimulation and consequently the hysteresis in the $I-V$ plot were not as substantial as in normal medium $(n=5$ of 5$)$ (Fig. $4 B 1, B 2$, gray traces). The current facilitated by the DLF and inhibited by SB-206553 was calculated by subtracting the current recorded after DLF stimulation in the presence of SB-206553 to the current recorded after DLF stimulation in normal medium (difference between gray traces in Fig. 4A1,B1). As illustrated in Figure 4C, SB-206553 only inhibited the inward current responsible for the hysteresis in $I-V$ plots. To quantify the effect of SB-206553, we compared the current facilitated by DLF stimulation (calculated as the difference of integrated current before and after DLF stimulation) before and after the addition of the $5-\mathrm{HT}_{2}$ antagonist. SB-206553 significantly inhibited the current facilitated by the DLF (paired $t$ test; $p<0.05 ; n=5$ ). Because the clockwise hysteresis corresponds to the activity of low-threshold L-type $\mathrm{Ca}^{2+}$ channels (Svirskis and Hounsgaard, 1997, 1998; Delgado-Lezama et al., 1997; Carlin et al., 2000) and because DLF stimulation did not affect the input resistance of motoneurons, we concluded that synaptic release of 5-HT activated 5- $\mathrm{HT}_{2}$ receptors, which were specifically facilitating low-threshold L-type $\mathrm{Ca}^{2+}$ channels $\left(\mathrm{Ca}_{\mathrm{V}} 1.3\right)$. 

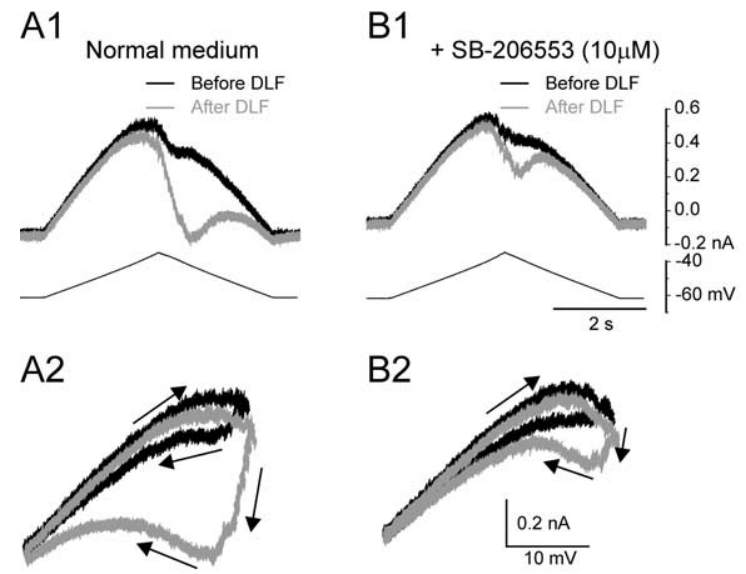

C

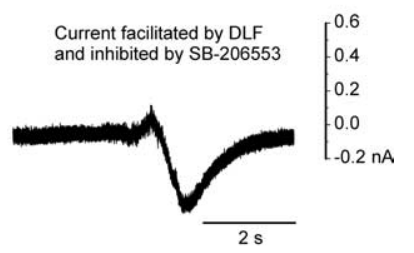

D

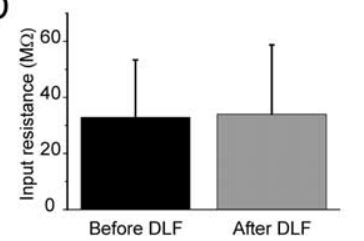

Figure 4. DLF-induced plateau currents are reduced by $5-\mathrm{HT}_{2}$ receptor antagonists. $\mathbf{A 1}$, Current recorded during triangular voltage command (bottom trace) before (black trace) and after (gray trace) stimulation of the DLF. DLF stimulation facilitated a slowly activating voltage-sensitive inward current. $\boldsymbol{A 2}, I-V$ plot of the recording. Note the facilitation of the clockwise hysteresis (arrows). B1, The same motoneuron recorded in the presence of SB-206553. The facilitation induced by the DLF was reduced. B2, $I-V$ plot. Note the lesser facilitation of the hysteresis. C, Current facilitated by the DLF and inhibited by SB-206553. The current blocked by SB-206553 corresponds to the one responsible for the hysteresis. $D$, Mean input resistance of motoneurons before (black) and after (gray) DLF stimulation was not statistically different. For all recordings, fast synaptic potentials were blocked by CNQX $(25 \mu \mathrm{M}), \mathrm{AP}-5(50 \mu \mathrm{M})$, strychnine $(10 \mu \mathrm{M})$, and bicuculline $(20 \mu \mathrm{m})$.

\section{Discussion}

Our study demonstrates that synaptic release of 5-HT induced by stimulation of the raphe nucleus promotes plateau potentials in spinal motoneurons. Moreover, it shows that the effect of 5-HT is attributable to the activation of $5-\mathrm{HT}_{2}$ receptors present on motoneurons and specifically activating a persistent inward current.

\section{Specificity of the effects induced by stimulation of the raphe nucleus}

A previous study performed in the cat showed that motoneuronal excitability is increased in response to raphe stimulation (Fung and Barnes, 1989). In agreement, we found that electrical stimulation in the ventral midline of the cut surface of the brainstem increased the excitability of motoneurons by facilitating plateau potentials. Although the stimulation electrode was positioned at the level of the nucleus raphe inferior (Cruce and Nieuwenhuys, 1974), one can argue that this does not ensure facilitation to be mediated by synaptically released 5-HT. First, serotonergic neurons also contain other transmitters such as enkephalins, substance P, or GABA (Schmidt and Jordan, 2000). Second, it is likely that the bipolar electrode recruited non-serotonergic neurons in the raphe nucleus (Schmidt and Jordan, 2000) or in its immediate surrounding. It was therefore necessary to perform pharmacological experiments to show that the facilitation induced by stimulation of the raphe nucleus was actually induced by 5 -HT. The fact that SB-206553 completely abolished the facilitation demonstrates that the main effect induced by the stimulation was caused by synaptic release of $5-\mathrm{HT}$ acting on $5-\mathrm{HT}_{2}$ receptors. Finally, the experiments performed with SB-206553 in a slice preparation in which ionotropic receptors were blocked strongly suggest that the $5-\mathrm{HT}_{2}$ receptors responsible for the facilitation are located on motoneurons. An alternative possibility would be that 5 -HT, acting on presynaptic terminals, induces the release of transmitters such as glutamate or acetylcholine, which are known to promote plateau potentials in motoneurons (Delgado-Lezama et al., 1997; Svirskis et al., 1998).
Timing of the effects induced by stimulation of the raphe nucleus The effects on the AHP and on the excitability of motoneurons were tested and detected 300-500 ms after stimulation of the raphe nucleus. To be valid, a test on the amplitude of the AHP or on excitability of motoneurons has to be performed from the same membrane potential as in the control condition. However, in most cases, stimulation of the raphe nucleus also induced excitatory synaptic potentials in motoneurons (data not shown), as reported by Fung and Barnes (1989). We ascribed these EPSPs to the recruitment of non-serotonergic fibers. The delay of intracellular test pulses in motoneurons was adjusted in order for the membrane potential not to be contaminated by any EPSP. Therefore, a value of $300 \mathrm{~ms}$ is probably an overestimation for the latency of the effects induced by the raphe nucleus.

The increase in excitability peaked $0.5 \mathrm{~s}$ after stimulation of the raphe nucleus and was still detectable after $8.5 \mathrm{~s}$. The excitability was back to its control level after $13.5 \mathrm{~s}$. Because it is unlikely that 5 -HT remains in the extracellular space for $>1.5 \mathrm{~s}$ (Hille, 2001), the increase in excitability can either be ascribed to a postsynaptic mechanism or to a prolonged firing of raphe neurons. This latter hypothesis can be discarded, because in slice preparations, stimulation of the DLF induced an increase in excitability of motoneurons with a similar time course.

\section{Multiple effects of 5-HT}

In motoneurons, 5-HT induces multiple effects including depolarization (Larkman and Kelly, 1992; Hsiao et al., 1997; Perrier et al., 2003), inhibition of the medium AHP following action potentials (Berger et al., 1992; Hsiao et al., 1997; Grunnet et al., 2004), and facilitation of plateau potentials (Hounsgaard et al., 1988a; Hounsgaard and Kiehn, 1989; Bennett et al., 2001; Perrier and Hounsgaard, 2003; Heckman et al., 2004). It was originally suggested that the facilitation of plateau potentials was a consequence of the inhibition of the AHP (Hounsgaard and Mintz, 1988; Schmidt and Jordan, 2000). Here, we show that synaptic release of 5-HT increases the excitability of motoneurons during a few seconds, both by inhibiting the AHP and by facilitating plateau potentials. Several lines of evidence suggest, however, that the two effects are attributable to different mechanisms occurring in parallel. First, a depolarizing current that did not generate action potentials before stimulation of the raphé spinal pathway induced action potentials afterward (Figs. $2 B, 3 B$ ). Inhibition of the AHP cannot explain this result. Second, voltageclamp experiments showed that the main current modulated by $5-\mathrm{HT}_{2}$ receptors after DLF stimulation is the one responsible for the hysteresis in $I-V$ plots (Fig. 4). This suggests that a specific pathway links $5-\mathrm{HT}_{2}$ receptors with the current responsible for the plateau potential. Third, the inhibition of the AHP is induced by the activation $5-\mathrm{HT}_{1 \mathrm{~A}}$ receptors in different types of motoneurons (Bayliss et al., 1995; Wikstrom et al., 1995) including turtle motoneurons (Grunnet et al., 2004). Thus, inhibition of the AHP and facilitation of plateau potentials are induced by two different subtypes of 5-HT receptors. 
Other studies have ascribed the facilitation of plateau by $5-\mathrm{HT}$ to the inhibition of a leak conductance that would enhance the persistent inward current responsible for plateau potentials (Heckman et al., 2003). In support of this idea, activation of $5-\mathrm{HT}_{1 \mathrm{~A}}$ receptors increases the input resistance of turtle motoneurons by inhibiting a leak conductance (Perrier et al., 2003). However, the experiments performed in the slice preparation show that stimulation of the DLF essentially modulates the inward current responsible for the hysteresis in $I-V$ plots (Fig. $4 A$ ) without significantly affecting the input resistance of motoneurons (Fig. 4D). This result implies a specific pathway between serotonergic receptors and L-type $\mathrm{Ca}^{2+}$ channels. This apparent discrepancy may be explained by the fact that, in the present study, the excitability of motoneurons was always tested several hundreds of milliseconds after synaptic release of transmitter, whereas in other studies, the increase in input resistance was observed during the continuous presence of 5-HT agonists in the extracellular medium. It is also possible that stimulation of the DLF or of the raphe nucleus was too brief to inhibit a leak conductance.

The persistent inward current recorded in slices was measured in the presence of the intracellular blocker of $\mathrm{Na}^{+}$channels, QX314 , applied through the microelectrode. This drug also reduces $\mathrm{Ca}^{2+}$ currents (Talbot and Sayer, 1996). However, stimulation of the DLF promoted a hysteresis, showing that an effect on $\mathrm{Ca}_{\mathrm{V}} 1.3$ current was minor. Nevertheless, we cannot exclude that QX-314 was partly responsible of the reduction of the hysteresis observed in the presence of the SB-206553.

\section{5-HT receptor subtype involved in the facilitation of plateau potentials}

Previous studies demonstrated that extracellular addition of the 5 - $\mathrm{HT}_{2 \mathrm{~A} / \mathrm{C}}$ receptor agonist $( \pm)$-1-(2,5-dimethoxy-4-iodophenyl)2-aminopropane hydrochloride (DOI) (Ichikawa and Meltzer, 1995) promotes plateau potentials in spinal motoneurons (Perrier and Hounsgaard, 2003). In the present study, we show that plateau potentials promoted by 5-HT are inhibited by SB-206553, which is an antagonist for 5- $\mathrm{HT}_{2 \mathrm{~B} / \mathrm{C}}$ receptor subtypes (Forbes et al., 1995). Therefore, it seems plausible that $5-\mathrm{HT}_{2 \mathrm{C}}$ receptors are responsible for the facilitation of plateau potentials in motoneurons.

\section{Functional considerations}

By showing that synaptic release of 5-HT induced by stimulation of the raphe nucleus promotes plateau potentials in motoneurons, we have established a mechanism by which the brain can regulate the excitability of motoneurons. In rats with complete spinal transections, activation of $5-\mathrm{HT}_{2 \mathrm{C}}$ receptors increases the ability of animals to perform weight-supported locomotion (Kim et al., 2001). Moreover, the $5-\mathrm{HT}_{2 \mathrm{~A} / \mathrm{C}}$ agonist DOI upregulates of the excitability of extensor motoneurons in acute spinal cats (Miller et al., 1996). Both observations could be explained by the facilitation of plateau potentials in extensor motoneurons. This hypothesis could be linked to the fact that plateau potentials promoted by 5-HT contribute to the shaping of the discharge pattern of motoneurons during withdrawal behaviors in frogs (Perrier and Tresch, 2005).

\section{References}

Alaburda A, Hounsgaard J (2003) Metabotropic modulation of motoneurons by scratch-like spinal network activity. J Neurosci 23:8625-8629.

Alvarez FJ, Pearson JC, Harrington D, Dewey D, Torbeck L, Fyffe RE (1998) Distribution of 5-hydroxytryptamine-immunoreactive boutons on alpha-motoneurons in the lumbar spinal cord of adult cats. J Comp Neurol 393:69-83.
Bayliss DA, Umemiya M, Berger AJ (1995) Inhibition of N- and P-type calcium currents and the after-hyperpolarization in rat motoneurones by serotonin. J Physiol (Lond) 485:635-647.

Bennett DJ, Li Y, Harvey PJ, Gorassini M (2001) Evidence for plateau potentials in tail motoneurons of awake chronic spinal rats with spasticity. J Neurophysiol 86:1972-1982.

Berger AJ, Bayliss DA, Viana F (1992) Modulation of neonatal rat hypoglossal motoneuron excitability by serotonin. Neurosci Lett 143:164-168.

Carlin KP, Jones KE, Jiang Z, Jordan LM, Brownstone RM (2000) Dendritic L-type calcium currents in mouse spinal motoneurons: implications for bistability. Eur J Neurosci 12:1635-1646.

Conway BA, Hultborn H, Kiehn O, Mintz I (1988) Plateau potentials in alpha-motoneurones induced by intravenous injection of L-dopa and clonidine in the spinal cat. J Physiol (Lond) 405:369-384.

Crone C, Hultborn H, Kiehn O, Mazieres L, Wigstrom H (1988) Maintained changes in motoneuronal excitability by short-lasting synaptic inputs in the decerebrate cat. J Physiol (Lond) 405:321-343.

Cruce WL, Nieuwenhuys R (1974) The cell masses in the brain stem of the turtle Testudo hermanni; a topographical and topological analysis. J Comp Neurol 156:277-306.

Delgado-Lezama R, Perrier JF, Nedergaard S, Svirskis G, Hounsgaard J (1997) Metabotropic synaptic regulation of intrinsic response properties of turtle spinal motoneurones. J Physiol (Lond) 504:97-102.

Derjean D, Bertrand S, Le Masson G, Landry M, Morisset V, Nagy F (2003) Dynamic balance of metabotropic inputs causes dorsal horn neurons to switch functional states. Nat Neurosci 6:274-281.

Eken T, Kiehn O (1989) Bistable firing properties of soleus motor units in unrestrained rats. Acta Physiol Scand 136:383-394.

Forbes IT, Ham P, Booth DH, Martin RT, Thompson M, Baxter GS, Blackburn TP, Glen A, Kennett GA, Wood MD (1995) 5-Methyl-1-(3-pyridylcarbamoyl)-1,2,3,5-tetrahydropyrrolo[2,3-f]indole: a novel 5-HT2C/ 5-HT2B receptor antagonist with improved affinity, selectivity, and oral activity. J Med Chem 38:2524-2530.

Fung SJ, Barnes CD (1989) Raphe-produced excitation of spinal cord motoneurons in the cat. Neurosci Lett 103:185-190.

Gorassini M, Bennett DJ, Kiehn O, Eken T, Hultborn H (1999) Activation patterns of hindlimb motor units in the awake rat and their relation to motoneuron intrinsic properties. J Neurophysiol 82:709-717.

Grunnet M, Jespersen T, Perrier JF (2004) 5-HT1A receptors modulate small-conductance $\mathrm{Ca}^{2+}$-activated $\mathrm{K}^{+}$channels. J Neurosci Res 78:845854.

Heckman CJ, Lee RH, Brownstone RM (2003) Hyperexcitable dendrites in motoneurons and their neuromodulatory control during motor behavior. Trends Neurosci 26:688-695.

Heckman CJ, Gorassini MA, Bennett DJ (2004) Persistent inward currents in motoneuron dendrites: implications for motor output. Muscle Nerve 31:135-156.

Hille B (2001) Ionic channels of excitable membranes. Sunderland, MA: Sinauer.

Hounsgaard J, Kiehn O (1989) Serotonin-induced bistability of turtle motoneurones caused by a nifedipine-sensitive calcium plateau potential. J Physiol (Lond) 414:265-282.

Hounsgaard J, Mintz I (1988) Calcium conductance and firing properties of spinal motoneurones in the turtle. J Physiol (Lond) 398:591-603.

Hounsgaard J, Kiehn O, Mintz I (1988a) Response properties of motoneurones in a slice preparation of the turtle spinal cord. J Physiol (Lond) 398:575-589.

Hounsgaard J, Hultborn H, Jespersen B, Kiehn O (1988b) Bistability of alpha-motoneurones in the decerebrate cat and in the acute spinal cat after intravenous 5-hydroxytryptophan. J Physiol (Lond) 405:345-367.

Hsiao CF, Trueblood PR, Levine MS, Chandler SH (1997) Multiple effects of serotonin on membrane properties of trigeminal motoneurons in vitro. J Neurophysiol 77:2910-2924.

Hsiao CF, del Negro CA, Trueblood PR, Chandler SH (1998) Ionic basis for serotonin-induced bistable membrane properties in guinea pig trigeminal motoneurons. J Neurophysiol 79:2847-2856.

Hultborn H (1999) Plateau potentials and their role in regulating motoneuronal firing. Prog Brain Res 123:39-48.

Ichikawa J, Meltzer HY (1995) DOI, a 5-HT2A/2C receptor agonist, potentiates amphetamine-induced dopamine release in rat striatum. Brain Res 698:204-208.

Inagaki S, Senba E, Shiosaka S, Takagi H, Kawai Y, Takatsuki K, Sakanaka M, 
Matsuzaki T, Tohyama M (1981) Regional distribution of substance P-like immunoreactivity in the frog brain and spinal cord: immunohistochemical analysis. J Comp Neurol 201:243-254.

Jacobs BL, Fornal CA (1997) Serotonin and motor activity. Curr Opin Neurobiol 7:820-825.

Kiehn O, Eken T (1997) Prolonged firing in motor units: evidence of plateau potentials in human motoneurons? J Neurophysiol 78:3061-3068.

Kiehn O, Rostrup E, Moller M (1992) Monoaminergic systems in the brainstem and spinal cord of the turtle Pseudemys scripta elegans as revealed by antibodies against serotonin and tyrosine hydroxylase. J Comp Neurol 325:527-547.

Kim D, Murray M, Simansky KJ (2001) The serotonergic 5-HT(2C) agonist $\mathrm{m}$-chlorophenylpiperazine increases weight-supported locomotion without development of tolerance in rats with spinal transections. Exp Neurol 169:496-500.

Larkman PM, Kelly JS (1992) Ionic mechanisms mediating 5-hydroxytryptamine- and noradrenaline-evoked depolarization of adult rat facial motoneurones. J Physiol (Lond) 456:473-490.

Lee RH, Heckman CJ (2000) Adjustable amplification of synaptic input in the dendrites of spinal motoneurons in vivo. J Neurosci 20:6734-6740.

Llinas RR (1988) The intrinsic electrophysiological properties of mammalian neurons: insights into central nervous system function. Science 242:1654-1664.

Miller JF, Paul KD, Lee RH, Rymer WZ, Heckman CJ (1996) Restoration of extensor excitability in the acute spinal cat by the 5-HT2 agonist DOI. J Neurophysiol 75:620-628.

Morisset V, Nagy F (1996) Modulation of regenerative membrane properties by stimulation of metabotropic glutamate receptors in rat deep dorsal horn neurons. J Neurophysiol 76:2794-2798.

Parent A, Poirier LJ (1971) Occurrence and distribution of monoaminecontaining neurons in the brain of the painted turtle, Chrysemys picta. J Anat 110:81-89.

Perrier JF, Hounsgaard J (1999) $\mathrm{Ca}^{2+}$-activated nonselective cationic current $(\mathrm{I}(\mathrm{CAN}))$ in turtle motoneurons. J Neurophysiol 82:730-735.

Perrier JF, Hounsgaard J (2003) 5-HT2 receptors promote plateau poten- tials in turtle spinal motoneurons by facilitating an L-type calcium current. J Neurophysiol 89:954-959.

Perrier JF, Tresch MC (2005) Recruitment of motor neuronal persistent inward currents shapes withdrawal reflexes in the frog. J Physiol (Lond) 562:507-520.

Perrier JF, Alaburda A, Hounsgaard J (2002) Spinal plasticity mediated by postsynaptic L-type $\mathrm{Ca}^{2+}$ channels. Brain Res Brain Res Rev 40:223-229.

Perrier JF, Alaburda A, Hounsgaard J (2003) 5-HT1A receptors increase excitability of spinal motoneurons by inhibiting a TASK-1-like $\mathrm{K}^{+}$current in the adult turtle. J Physiol (Lond) 548:485-492.

Russo RE, Hounsgaard J (1994) Short-term plasticity in turtle dorsal horn neurons mediated by L-type $\mathrm{Ca}^{2+}$ channels. Neuroscience 61:191-197.

Schmidt BJ, Jordan LM (2000) The role of serotonin in reflex modulation and locomotor rhythm production in the mammalian spinal cord. Brain Res Bull 53:689-710.

Schwindt P, Crill WE (1977) A persistent negative resistance in cat lumbar motoneurons. Brain Res 120:173-178.

Svirskis G, Hounsgaard J (1997) Depolarization-induced facilitation of a plateau-generating current in ventral horn neurons in the turtle spinal cord. J Neurophysiol 78:1740-1742.

Svirskis G, Hounsgaard J (1998) Transmitter regulation of plateau properties in turtle motoneurons. J Neurophysiol 79:45-50.

Talbot MJ, Sayer RJ (1996) Intracellular QX-314 inhibits calcium currents in hippocampal CA1 pyramidal neurons. J Neurophysiol 76:2120-2124.

Ten Donkelaar HJ (1976) Descending pathways from the brain stem to the spinal cord in some reptiles. I. Origin. J Comp Neurol 167:421-442.

Ueda S, Takeuchi Y, Sano Y (1983) Immunohistochemical demonstration of serotonin neurons in the central nervous system of the turtle (Clemmys japonica). Anat Embryol (Berl) 168:1-19.

Uhl GR, Goodman RR, Kuhar MJ, Childers SR, Snyder SH (1979) Immunohistochemical mapping of enkephalin containing cell bodies, fibers and nerve terminals in the brain stem of the rat. Brain Res 166:75-94.

Wikstrom M, Hill R, Hellgren J, Grillner S (1995) The action of 5-HT on calcium-dependent potassium channels and on the spinal locomotor network in lamprey is mediated by 5-HT1A-like receptors. Brain Res 678:191-199. 